\title{
Transforming post-Catholic Ireland - Religious Practice in Late Modernity de Gladys Ganiel
}

\section{Catherine Maignant}

\section{OpenEdition}

1 Journals

\section{Édition électronique}

URL : http://journals.openedition.org/etudesirlandaises/5066

DOI : 10.4000/etudesirlandaises.5066

ISSN : 2259-8863

\section{Éditeur}

Presses universitaires de Caen

\section{Édition imprimée}

Date de publication : 30 novembre 2016

Pagination : 195-197

ISBN : 978-2-7535-5358-3

ISSN : 0183-973X

Référence électronique

Catherine Maignant, «Transforming post-Catholic Ireland - Religious Practice in Late Modernity de Gladys Ganiel », Études irlandaises [En ligne], 41-2 | 2016, mis en ligne le 30 janvier 2016, consulté le 24

septembre 2020. URL : http://journals.openedition.org/etudesirlandaises/5066 ; DOI : https://doi.org/ 10.4000/etudesirlandaises.5066

\section{(c) (†)(9)}

Études irlandaises est mise à disposition selon les termes de la Licence Creative Commons Attribution

- Pas d'Utilisation Commerciale - Partage dans les Mêmes Conditions 4.0 International. 
Ses collines sont toujours bleues, l'eau de ses rivières bouillonnantes Court par-dessus les rochers.

The final lines of the journal achieve a form of hopeful if weary acceptance, at the very end of 1938 :

On aura le temps plus tard d'examiner

Les comptes, plus tard le soleil brillera

Et l'équation sera résolue à la fin.

With the recent renewed interest in Louis MacNeice's work in France, Haberer's impressive translation of Autumn Journal, so clearly informed by his deep study of the poet, is certain to provide unprecedented insights.

Elizabeth Pearce

University of Melbourne

Gladys Ganiel, Transforming post-Catholic Ireland - Religious Practice in Late Modernity, Oxford, Oxford University Press, 2016, 273 p., ISBN 978-0-19-874578-5.

Transforming post-Catholic Ireland est le résultat d'un travail de recherche action mené par une équipe pilotée par Gladys Ganiel, chercheuse à l'Institut d'étude de transformation des conflits et de justice sociale (ISCTSJ) à Queen's University Belfast, dans le cadre de son activité militante au sein de l'Irish School of Ecumenics. L'ouvrage vise tout à la fois à évaluer la diversité religieuse dans l'île d'Irlande, en lien avec les questions d'immigration et de réconciliation, et à proposer des pistes pour faire en sorte que la religion puisse contribuer, mieux qu'aujourd'hui, à la complexe édification de la paix au sens le plus large.

Ganiel s'inscrit ainsi en faux contre des théories telles que celle de Beck ( $A$ God of One's Own: Religion's Capacity for Peace and Potential for Violence, CUP, 2010), qui vise à démontrer que l'individu réflexif moderne tend à créer ses propres dieux hors de toute institution, ce qui serait facteur de tolérance et d'ouverture à l'autre, sur la base d'une recherche de la paix plutôt que de la vérité. Selon Ganiel, les avancées en ce domaine seraient davantage le fait d'organisations religieuses qu'elle nomme " extra-institutionnelles " dont la caractéristique principale est de garder des liens forts avec les institutions à la marge desquelles elles se situent.

Afin de tester ses hypothèses, son équipe a mené en 2009 deux enquêtes, la première, directe, auprès de plus de 4000 chefs religieux, dont quelque 700 ont répondu, et la seconde, en ligne, qui a reçu plus de 900 réponses. Fort de ces données, l'ouvrage 
passe en revue un panel de groupes religieux ou para-religieux, œcuméniques ou non, souvent multiethniques, s'inscrivant, pour l'essentiel, dans une démarche chrétienne, et dont la particularité est d'adopter une position critique vis-à-vis de leur institution de référence, que ce soit l'Église catholique ou les Églises protestantes, presbytérienne, méthodiste ou autre. À noter une passionnante enquête sur le développement en Irlande du Pentecôtisme et l'émergence de groupes charismatiques évangéliques, notamment d'origine africaine (ainsi le Jesus Centre à Dublin).

Seul un chapitre évoque la question des religions dites minoritaires (Bouddhisme, Islam, Sikhisme, Hindouisme, Bahải), auxquelles s'ajoutent les athées. Il n'est plus question alors de religions « extra-institutionnelles " mais des difficultés rencontrées par les minorités religieuses dans une Irlande encore très fortement marquée par le catholicisme malgré l'apparente sécularisation. Le faible nombre de personnes interrogées (10 pour l'ensemble des religions minoritaires, dont 5 Irlandais convertis) limite la portée scientifique des résultats présentés dans cette section. L'auteure est manifestement davantage intéressée par le renouveau du christianisme à partir de ses marges, qu'elle voit comme une source d'espoir dans la perspective de son action engagée au service de l'œcuménisme, particulièrement en Irlande du Nord, dans un contexte ou la réconciliation demeure difficile.

Les conclusions de l'enquête se résument aux constats suivants : l'Église catholique, massivement rejetée, notamment en raison des scandales récents auxquels elle est associée, demeure l'institution de référence à la fois au Nord et au Sud. Les tendances identifiées par Ganiel confirment les analyses de ses prédécesseurs au niveau du monde occidental : individualisation et désinstitutionnalisation en sont les maîtres-mots. L'épanouissement personnel résulte de la libération des entraves et de la participation à des initiatives à visée à la fois sociale et religieuse. Le sectarisme sous toutes ses formes demeure toutefois latent et le terme d'œcuménisme est peu compris, voire polémique, au moins dans sa définition. La preuve, enfin, n'est pas faite de l'aptitude des groupes " extra-institutionnels » à faire évoluer les institutions et la société depuis la périphérie, même s'ils en ont le potentiel et l'envie. La fragmentation et la faible masse critique de ces organisations limitent en effet la portée de leur action.

L'ouvrage de Ganiel est tout à fait intéressant. Il a le mérite de faire découvrir aux lecteurs des groupes religieux ou para-religieux peu connus qui contribuent au pluralisme, à l'intégration des minorités ethniques et à l'évolution identitaire de l'Irlande. Il situe également son analyse dans le cadre plus large des débats théoriques et conceptuels de sociologie des religions sans jamais s'éloigner des préoccupations politiques et sociales propres à l'Irlande, tant au nord qu'au sud. L'ambition du travail est considérable et l'ouvrage malheureusement bien court pour rendre compte de la richesse manifeste des données accumulées. Les notions de religion " extra-institutionnelle " et d'Irlande " post-catholique " demeurent 
aussi un peu discutables par certains de leurs aspects, d'autant que l'engagement de l'auteure dans l'action œcuménique est revendiquée. Il n'en demeure pas moins que l'originalité, la richesse et l'orientation thématique de Transforming postCatholic Ireland en font une lecture indispensable pour toute personne intéressée par les évolutions religieuses de l'Irlande contemporaine.

Catherine Maignant

Étienne Bours, La Musique irlandaise, Paris, Fayard, 2015, 576 p. ISBN 978-2213-67511-4.

Un ouvrage complet et grand public en français sur la musique irlandaise, cela n'était pas arrivé depuis 1995! Et c'est une grande maison d'édition française qui prend le risque, sans doute limité si l'on en juge par la popularité de cette musique, qui ne se dément pas à l'échelle mondiale dans le grand public depuis maintenant plus de 50 ans.

Son auteur, le journaliste Etienne Bours, est avant tout un passionné : par son métier de conseiller à la Médiathèque PointCulture de Belgique, par ses émissions de radio à la RTBF1, par ses ouvrages sur les musiques du monde et le folk, c'est sans doute l'un des francophones les mieux placés pour proposer une vision globale des musiques traditionnelles aujourd'hui, et notamment de la musique irlandaise.

Nous tenons donc entre les mains un gros ouvrage de 576 pages préfacé par le chanteur breton Gilles Servat, et qui fourmille d'informations dans un style très accessible. L'ensemble est divisé en deux parties bien distinctes : une première se concentre sur l'histoire de l'Irlande en chansons, tandis qu'une seconde se penche sur l'histoire de la musique, suivies d'un résumé des principales dates de l'histoire du pays, d'une discographie, d'une courte filmographie et d'une longue bibliographie, ensemble complété par trois index (chansons, noms propres et termes).

Le principal point fort de cet ouvrage, outre cette passion et cette subjectivité évidentes, sera donc le lien constant établi entre l'histoire de la musique irlandaise et l'histoire du pays, et plus précisément les «liens qui unissent musique et société » comme l'auteur l'explicite dès l'introduction et le répète tout au long de l'ouvrage.

Il tisse ainsi dans cette première partie le fil de l'histoire de l'Irlande à travers ses chansons, passant en revue les périodes fastes et les invasions, les espoirs et les rancœurs, non sans adopter un cynisme finalement bien irlandais, comme en témoigne l'affirmation en début d'ouvrage selon laquelle "L'Irlande a mal à son histoire et la musique est son remède ». La deuxième partie examine, pour l'essentiel, les différents genres de musique instrumentale ainsi que les instruments pra- 